\title{
Recent progress on the study of
}

\section{the microstructure and mechanical properties of ECAE copper}

\author{
Journal Article \\ Author(s): \\ Dalla Torre, Florian H.; Gazder, Azdiar A.; Pereloma, Elena V.; Davies, Christopher H.J. \\ Publication date: \\ 2007 \\ Permanent link: \\ https://doi.org/10.3929/ethz-b-000003330 \\ Rights / license: \\ In Copyright - Non-Commercial Use Permitted \\ Originally published in: \\ Journal of Materials Science 42(5), https://doi.org/10.1007/s10853-006-1283-1
}




\title{
Recent progress on the study of the microstructure and mechanical properties of ECAE copper
}

\author{
Florian H. Dalla Torre · Azdiar A. Gazder • \\ Elena V. Pereloma · Christopher H. J. Davies
}

Received: 2 June 2006/ Accepted: 9 November 2006/ Published online: 30 January 2007

(C) Springer Science+Business Media, LLC 2007

\begin{abstract}
Results on the microstructure and the tensile properties of equal channel angular extruded (ECAE) copper processed for one to 16 passes are presented and compared with the available literature data. With increasing number of passes $(N)$, the microstructure changes from a strongly elongated shear band structure after $N=1$ and 2, towards a more equiaxed subgrain and grain structure. This is accompanied by a decrease in the cell wall or subgrainboundary widths and an increase in recovered or even recrystallised grain structures with low dislocation densities. Electron backscatter diffraction measurements have indicated that for lower $N$, the location of $\Sigma 3$ boundaries is restricted to shear bands, while at greater $N, \Sigma 3$ boundaries were found to be more widely distributed. Texture measurements indicate close similarity with simple shear texture components and a spread of the orientation components with greater $N$. Upon comparing the tensile behaviour of as-ECAE $\mathrm{Cu}$ with the surveyed literature, broad agreement on the strength of the material is achieved. However, a strong variation in the percentage elongation to failure is also noted. Strain hardening and deformation kinetic
\end{abstract}

F. H. Dalla Torre $(\bowtie)$

Laboratory of Metal Physics and Technology, Department of Materials, ETH Zurich, Wolfgang-Pauli-Str. 10, 8093

Zurich, Switzerland

e-mail: Florian.DallaTorre@mat.ethz.ch

A. A. Gazder · E. V. Pereloma · C. H. J. Davies

Department of Materials Engineering, Monash University, Clayton, Victoria 3800, Australia

A. A. Gazder · E. V. Pereloma · C. H. J. Davies

Victorian Centre for Advanced Materials Manufacturing,

Belmont, Victoria, Australia analysis via strain rate jump tests indicate an evolution from stage III to $\mathrm{V}$ hardening during post-ECAE compression and a saturation in the strain rate sensitivity after $N=4$ resulting in maximum values of $\sim 0.02$. Our results suggest that rather than a change in deformation mechanism, the increase in ductility with increasing $N$ is associated with an increase in the mean free path of dislocations-with the grain boundaries remaining actively involved as the transmitter of plastic strain and their interaction with dislocations being the rate controlling deformation mechanism.

\section{Introduction}

Copper $(\mathrm{Cu})$ represents an ideal model material to study the process of deformation and recrystallisation due to its intrinsic softness and formability, low cost, fcc crystal structure and medium stacking fault energy. In early studies on 'large plastic deformation', $\mathrm{Cu}$ was often chosen for deformation experiments which were conducted using conventional methods such as rolling, torsion, extrusion or compression, all of which are capable of imparting large strains to the workpiece ([1-3] and the references therein). These and other studies conducted between 1950-1980 represent the basis of our understanding of the material's properties and its associated microstructure resulting from severe plastic deformation (SPD), a term coined by Russian researchers in the 1980s (see ref [4] among others). Compared to classical deformation processes, the big advantage of SPD techniques (represented in particular by equal channel angular extrusion (ECAE) $[5,6]$ and high pressure torsion (HPT) [7-9]) is the lack of 
shape-change post-deformation and the consequent possibility to impart extremely large strains. Thanks to Gleiter's research on nanocrystalline materials [10,11], SPD has received enormous interest over the past two decades as a method capable of producing fully dense and bulk nanostructured materials. In this context, $\mathrm{Cu}$ has remained the best-studied material and has only recently been outnumbered by publications on steels mainly due to the large demand for the latter in Asia [12]. Knowledge of the amount of accumulated strain required to achieve a stable end micro- or nanostructure is important should the so-produced materials enter future industrial applications. Towards this end, a comparison of experimental results with published literature using similar deformation procedures is necessary to evaluate the sensitivity of the material to the type of apparatus used.

Thus, this study aims to summarise microstructural results on ECAE processed $\mathrm{Cu}$. A survey of microstructural evolution with emphasis on the grain size and twin formation is presented. Based on previous work, we focus on deformation at room temperature (RT) with a die angle of $\Phi=90^{\circ}$, a sharp outer die corner $\left(\Psi=0^{\circ}\right)$ and a clockwise $90^{\circ}$ rotation of the billet along its longitudinal direction between successive passes. This so called route $\mathrm{B}_{\mathrm{C}}$ has proven to show the most efficient procedure by which an equiaxed subgrain or grain structure of minimum dimensions can be achieved [13-15]. Moreover this paper discusses and reviews the post-ECAE deformation behaviour in compression and tension. The tensile elongation and the hardening behaviour during compression testing are also emphasised.

\section{Experimental details}

Commercially available, high purity $(>99.95 \%) \mathrm{Cu}$ rods $\left(20 \times 20 \times 80 \mathrm{~mm}^{3}\right)$ were annealed at $873 \mathrm{~K}$ for $2 \mathrm{~h}$ in an inert atmosphere resulting in a mean grain size of $\sim 20 \pm 16 \mu \mathrm{m}$. Three die inserts were arranged to form an L-shaped channel within the ECAE die cradle (Fig. 1). Room temperature (RT), $\Phi=90^{\circ}$ and $\Psi=0^{\circ}$ ECAE was performed with a constant forward speed $\left(2 \mathrm{~mm} \mathrm{~s}^{-1}\right)$ and back-pressure $(60 \mathrm{MPa})$ for up to $N=1,2,4,8,12$ and 16 passes via route $\mathrm{B}_{\mathrm{C}}$. While larger magnitudes of back pressure have been shown to promote billet homogeneity $[16,17]$, the back pressure used in the present study serves mainly to allow for efficient and complete filling of the die channel during ECAE and also enables the billet to roughly keep its original rectangular shape. Moreover, due to the nature of the die set-up and applied hydrostatic

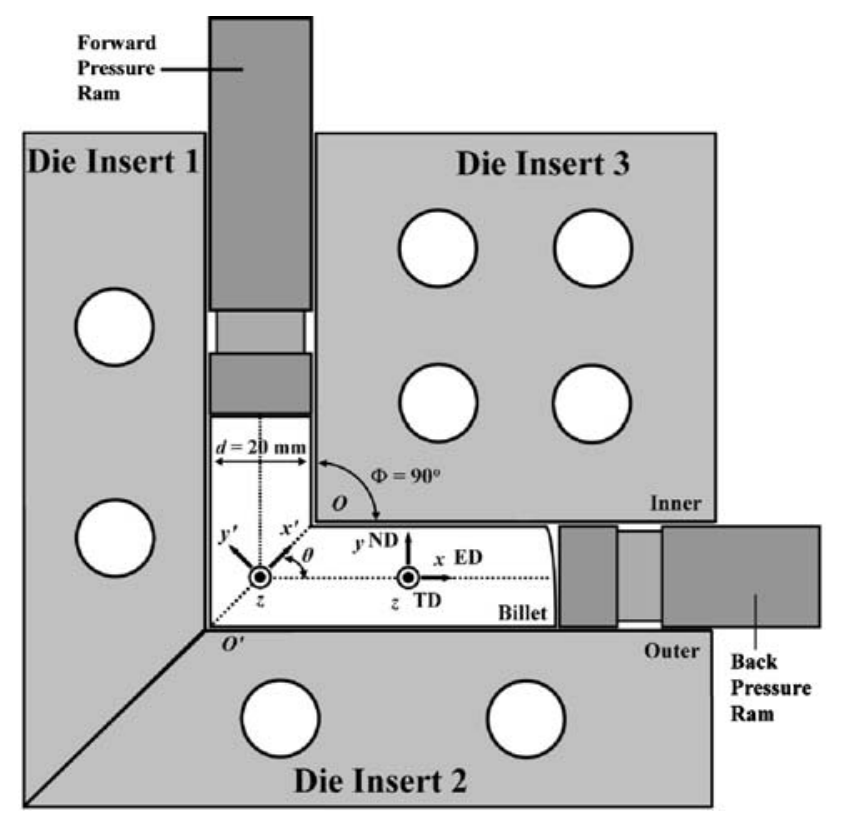

Fig. 1 Schematic of ECAE tooling and $\Phi=90^{\circ}$ die set-up

pressures, a slight swelling of the billet across its thickness also occurs, which effectively locks the billet in between the die walls of the exit channel. Consequently, removing the three die inserts allows for easy retrieval of the billet after each pass. Between successive passes, the billets were ground back to their original dimensions using a water soluble oil (Shell Dromus- $\mathrm{B}^{\mathrm{TM}}$ in a 40:1 water and oil ratio) which served as both lubricant and cooling medium. Considering the machining undertaken to fit the billet back into the entry channel for successive passes, slightly shorter billets with increasing $N$ are expected. Additionally, billets and specimens were stored at RT between extrusions and before and during microstructural analysis, respectively.

Specimens for microstructural characterisation via transmission electron microscopy (TEM), X-ray diffraction (XRD) and Electron Back-Scatter Diffraction (EBSD) were cut perpendicular to the extrusion direction (ED) from the center of the uniformly sheared billet length and are referred to as the $x$-plane samples.

Thin foils of the $x$-plane samples for transmission electron microscopy (TEM) were prepared by electrolytic thinning (for more details, please refer to [18]). EBSD measurements were performed on a LEO-1530 FEG-SEM fitted with a Nordlys-II ${ }^{\mathrm{TM}}$ EBSD detector. Mostly, a scan area of $10 \times 18 \mu \mathrm{m}^{2}$ with a 40 or $80 \mathrm{~nm}$ step size was used. In some specific cases, larger scans of up to $25 \times 50 \mu \mathrm{m}^{2}$ were also performed. Postprocessing of the raw data was undertaken using 
VMAP $[19,20]$ and HKL-Channel 5. For grain and subgrain size measurements, the equivalent circle diameter (ECD) method was used, wherein the area is measured and the grain/subgrain size is defined as the diameter of a circle with the area of the grain. In the 256-colour EBSD maps, the various colours represent the different Euler angles of each volume element with a $5^{\circ}$ angular variation. Note that these Euler angles refer to specimen directions when inserted in the microscope and therefore, do not generally correspond to the Euler angles conventionally used to describe a deformed material. In many cases, regions of similar orientation have similar colours; however, this is not always the case due to the discontinuities in Euler space [19].

Texture analysis was performed on $20 \times 20 \times 3 \mathrm{~mm}^{3}$ ED-samples using a GBC-MMA texture goniometer working at $40 \mathrm{kV}$ and $25 \mathrm{~mA}$ and equipped with a $\mathrm{Cu}-\mathrm{K}_{\alpha}$ anode and a polycapillary beam enhancer, resulting in a collimated beam of $10 \times 10 \mathrm{~mm}^{2}$. Raw data in the form of incomplete pole figures (PFs) $\left(\chi=0^{\circ}\right.$ to $\left.80^{\circ}\right)$ from the (111), (200), and (220) crystallographic planes were used to calculate the orientation distribution functions (ODFs) $f(g)$ using the spherical harmonic method without imposing any sample symmetry conditions. $g=\left(\varphi_{1}, \varphi, \varphi_{2}\right)$ refers to grain orientation denoted by the three Euler angles in Bunge's notation [21]. All end-texture PFs and ODFs were subsequently rotated to TD-view and will be discussed in the $x y z$ laboratory system (Fig. 1). Correspondingly, the TD, ED and ND-axes are denoted along the $\varphi_{1}, \varphi$ and $\varphi_{2}$ directions, respectively. Further details regarding the ideal texture components developed during ECAE are included in Table 2.

In order to produce tension and compression specimens, the billets were first sectioned into quarters. Three such sections were used to produce the circular tensile specimens with a diameter of $4 \mathrm{~mm}$ and a gage length of $25 \mathrm{~mm}$. Correspondingly, the center of the fourth section was used to produce cylindrical compression test samples of $4 \mathrm{~mm}$ diameter and $8 \mathrm{~mm}$ length. The tensile tests were performed at RT on a screw-driven Instron operating at a cross head speed of $2.5 \mathrm{~mm} \mathrm{~min}^{-1}$, resulting in a starting strain rate of $\varepsilon=1.6 \times 10^{-3} \mathrm{~s}^{-1}$. The strain was measured with a clip-gage mounted directly onto the tensile specimens, yielding a Youngs modulus of about $130 \mathrm{GPa}$, in close agreement with the theoretical value of $\mathrm{Cu}$. It should be noted that while the gage length is situated well within the uniformly sheared stable billet length for $N \leq 8$, the gage lengths of specimens machined after $N=12$ and 16 could contain non-uniformly sheared volumes. For the compression tests, a cross head speed of $0.5 \mathrm{~mm} \mathrm{~min}^{-1}$ was used on the same screw-driven Instron resulting in an initial strain rate of $\varepsilon=1 \times 10^{-3} \mathrm{~s}^{-1}$. Cyclic strain rate jump tests in compression were performed on a hydraulic Instron to evaluate the influence on strain rate sensitivity of $N$. The strain rate jumps were performed between $1 \times 10^{-4}$ and $1 \times 10^{-2} \mathrm{~s}^{-1}$. In both type of compression tests, the strain was measured by the cross-head displacement only, which due to the machine compliance leads to a significantly lower apparent Youngs modulus in the uncorrected stress-strain curves shown in Section 5. Beyond $30 \%$ strain a steady increase in the stress with strain has been associated with the gradual increase in frictional forces. Hence only data below $30 \%$ strain were considered as valid for the analysis.

\section{Microstructure of ECAE processed Cu}

In this section, a survey on ECAE Cu is presented with the idea of imparting a general description of the microstructure and to highlight the typical features found by several research groups. For comparison of subgrain and grain size measurements, the available literature data has been compiled in Table 1 .

In the early 1990's, studies on the microstructure of SPD metals produced via HPT or ECAE were conducted by the Russian group led by Prof. R.Z. Valiev. The research was mainly focussed on characterising the end-physical properties of SPD materials after a minimal (preferably, nano-sized), homogeneous grain structure was reached. The differences between these 'ultra-fine grained' (UFG) metals and their coarse-grained counterparts [22-24] in terms of their elastic moduli, diffusion coefficients, internal friction, Curie and Debye temperatures and superplasticity was highlighted and attributed to their small grain sizes and the development of non-equilibrium grain boundaries [23, 25-27].

One of the first mentioned studies on ECAE $\mathrm{Cu}$ processed at RT up to $N=4$ passes using route $\mathrm{B}_{\mathrm{C}}$ led to an equiaxed grain structure and an average grain size of $210 \mathrm{~nm}$ [27]. The authors observed that smaller grains $(<100 \mathrm{~nm})$ with a volume fraction of $\sim 15 \%$ were absent of lattice dislocations, while larger grains (400-500 nm) with a volume fraction of $\sim 48 \%$ indicate the presence of a cell structure with subgrain boundaries and the presence of lattice dislocations having a mean density inside grains of $5 \times 10^{14} \mathrm{~m}^{-2}$ [27]. About $37 \%$ of the volume is reported to be constituting of intermediate grains of $100-200 \mathrm{~nm}$ in size with a 'chaotic dislocation structure' [27].

Similarly, Ferasse et al. [14] also investigated the effect of the number of passes on pure $\mathrm{Cu}$ and 
Table 1 Grain and subgrain size measurements of ECAE-Cu for varying number of passes and processing routes taken from various references and own data

\begin{tabular}{|c|c|c|c|c|c|c|c|c|c|}
\hline \multicolumn{5}{|c|}{ Processing Parameters } & \multirow[t]{3}{*}{ Method } & \multirow{3}{*}{$\begin{array}{l}\text { Avg. } \\
\text { Grain } \\
\text { Size [nm] }\end{array}$} & \multirow{3}{*}{$\begin{array}{l}\text { Avg. } \\
\text { Subgrain / } \\
\text { Cell Size[nm] }\end{array}$} & \multirow{3}{*}{$\begin{array}{l}\text { \% Volume } \\
\text { HAGB }\end{array}$} & \multirow[t]{3}{*}{ Ref. } \\
\hline \multicolumn{2}{|c|}{ ECAE Die Angle } & \multirow[t]{2}{*}{ Passes $(N)$} & \multirow[t]{2}{*}{ Route } & \multirow{2}{*}{$\begin{array}{l}\text { Sample } \\
\text { Plane* }\end{array}$} & & & & & \\
\hline $\begin{array}{l}\text { Inner Angle } \\
(\Phi)\end{array}$ & $\begin{array}{l}\text { Outer Angle } \\
(\Psi)\end{array}$ & & & & & & & & \\
\hline 90 & - & 4,12 & $\mathrm{~B}_{\mathrm{C}}$ & $x$ & TEM & 210 & - & - & {$[4,27]$} \\
\hline 90 & - & 4 & $\mathrm{~B}_{\mathrm{C}}$ & - & TEM BF & $200-300$ & - & - & [14] \\
\hline 90 & - & 14 & $\mathrm{C}$ & $x$ & $\begin{array}{l}\text { TEM, } \\
\text { EBSD }\end{array}$ & 200 & - & $\sim 70$ & [28] \\
\hline 90 & 45 & 8 & $\mathrm{~B}_{\mathrm{C}}$ & $y$ & TEM & $200-2000$ & $200-400$ & 37 & {$[29,30]$} \\
\hline 90 & 0 & 8 & $\mathrm{~B}_{\mathrm{C}}$ & $y$ & TEM & $200-2000$ & $200-300$ & 29 & {$[30]$} \\
\hline 90 & 20 & $1-8$ & $\mathrm{C}$ & - & TEM, BF & & 200 & & [36] \\
\hline 90 & - & $1-12$ & $\mathrm{~B}_{\mathrm{C}}$ & $x$ & TEM, DF & 250 & & $\uparrow$ with $N$ & [38] \\
\hline 90 & - & 8 & $\mathrm{~B}_{\mathrm{C}}$ & $x$ & TEM, BF & $300-400$ & (ignored) & - & [39] \\
\hline 90 & - & 8 & $\mathrm{~B}_{\mathrm{C}}$ & & TEM, BF & 300 & & - & [40] \\
\hline 90 & 20 & 8 & $\mathrm{~B}_{\mathrm{C}}$ & $x$ & TEM, BF & 500 & 150 & 30 & [41] \\
\hline 90 & 20 & 8 & $\mathrm{C}$ & $x$ & TEM, BF & 950 & 190 & 20 & [41] \\
\hline 90 & - & 10 & $\mathrm{~B}_{\mathrm{C}}$ & $x$ & TEM, BF & & $200-250$ & - & [42] \\
\hline 90 & - & 4 & $\mathrm{~B}_{\mathrm{C}}$ & - & TEM & 300 & & - & [43] \\
\hline 90 & - & 16,20 & A & $y$ & EBSD & 420,370 & - & 68,72 & {$[37,44]$} \\
\hline 90 & - & 16,20 & $\mathrm{~B}_{\mathrm{C}}$ & $y$ & EBSD & 490,390 & - & 67,71 & {$[37,44]$} \\
\hline 92 & - & 8 & $\mathrm{~B}_{\mathrm{C}}$ & - & TEM & - & 400 & - & [46] \\
\hline 90 & 0 & $4 \geq N \leq 16$ & $\mathrm{~B}_{\mathrm{C}}$ & $x$ & EBSD & 200 & 120 & 45 & own data \\
\hline 90 & 0 & $4 \geq N \leq 16$ & $\mathrm{~B}_{\mathrm{C}}$ & $x$ & TEM & - & 170 & - & own data \\
\hline
\end{tabular}

* Legend: The various sample planes are represented perpendicular to the directions $x, y, z$ as denoted in the coordinate system as defined by Fig. 1. EBSD measurements have been performed with a step size of $40 \mathrm{~nm}$

concluded that after $N=4$, grain refinement reaches a minimal size of $200-300 \mathrm{~nm}$, concurrent with a stabilisation of strength and hardness. Their results on the grain size measured by TEM were later confirmed by Mishin and Gottstein [28] who, apart from dislocation density estimates of $5 \times 10^{14} \mathrm{~m}^{-2}$ (in agreement with the value given by $[25,27])$, reported the occurrence of twins formed during ECAE and a major fraction of random high-angle grain boundaries (HAGBs). However, the latter observation has been proven incorrect in a subsequent work by Mishin et al. [29, 30] which concentrated on detailed misorientation measurements of the ECAE substructure deformed up to $N=8$, at $\Phi$ $=90^{\circ}$ via route $B_{C}$. Misorientation measurements on 219 misorientations showed that $63 \%$ are low-angle grain boundaries (LAGBs) and that the intragranular volumes are never surrounded solely by HAGBs. Statistical measurements revealed a HAGB spacing perpendicular to the dominant band structure between $0.2 \mu \mathrm{m}$ and $2 \mu \mathrm{m}$. In agreement with the comprehensive investigation of Agnew [31], Mishin et al. [29, 30] concluded that: (i) the reported grains size of $0.2 \mu \mathrm{m}$ to $0.3 \mu \mathrm{m}$ measured on ECAE $\mathrm{Cu}$ included boundaries of high- and low-angle and, (ii) ECAE deformed metals should rather be characterised in terms of deformation structures rather than be classified as a 'UFG' material.
These authors $[29,31]$ further recognised that ECAE $\mathrm{Cu}$ exhibits elongated subgrain structures, which are subdivided transversely by low-angle boundaries similar to what has been observed as 'incident dislocation boundaries' in cold-rolling deformed structures [32]. An important point highlighted in [33] concerns the technique of measuring misorientations by means of TEM selected area diffraction (SAD) patterns. Measurements based on SAD patterns as performed in [13, 34,35 ] do not account for misorientations adjacent to a grain, leading to an overestimation of the volume of HAGBs in ECAE metals [33]. This was explained on the basis of the spatial limitation in conventional TEM studies with large diaphragms (in the micrometerrange) yielded diffraction patterns from multiple boundaries (which in bright-field (BF) mode were shown to be spaced only few hundreds of nanometers apart).

Several other TEM studies have quantitatively reproduced microstructures similar to those characterised above [36-44]. However, in most of these studies the 'grain' size has been defined by the shape of the boundaries rather than by an accurate statistical misorientation measurement. These results indicate an average size between $200 \mathrm{~nm}$ and $400 \mathrm{~nm}$ with a typical log-normal distribution function spread from 
$100 \mathrm{~nm}$ to $600 \mathrm{~nm}$ (see Table 1). In order to differentiate between the high and low misorientation angles of the boundaries, dark-field (DF) images were proposed for grain size measurements. However, these studies also yielded similar grain sizes to previous calculations based on BF images [38].

The microstructural evolution of $\mathrm{Cu}$ processed via route $\mathrm{C}$ for $N=1-8$ passes has been studied by Baik et al. [36] in order to deduce the mean 'cell size' as a function of $N$. They observed a minimum value of $\sim 200 \mathrm{~nm}$ peak cell sizes already after the first pass, but indicated a decrease in the spread of the cell size distribution with increasing $N$. On the other hand, using a $\Phi=90^{\circ}$ die Huang et al. [41] studied the influence of the strain path via routes $B_{C}$ and $C$ for up to $N=8$ by comparing the microstructural differences with respect to sample orientations $x$ and $z$ (see Fig. 1). They showed that while the $x$-plane of the microstructure of route $\mathrm{B}_{\mathrm{C}}$ and $\mathrm{C}$ samples exhibited a nearly equiaxed cell/subgrain structure, the $z$-plane indicated a higher fraction of elongated cells/subgrains for both routes by approximately the same amount. In agreement with previous results [13-15], they observed a smaller grain and cell/subgrain size and a higher fraction of HAGBs for route $B_{C}$ compared to route C. Analysis of 100 boundaries indicated that LAGBs always showed a diffused appearance due to the dense dislocation forests at the boundaries. Alternatively, HAGBs comprised sharp contrast and mainly dislocation-free adjacent areas [41]. Their observation and the statistical TEM misorientation measurements of Mishin et al. [29] now serve as a guide for qualitatively measuring the misorientation from the boundary morphology in order to achieve higher statistics.

\section{Microstructural evolution of as-ECAE Cu}

Upon adopting the methodology of Huang et al. [41], our microstructure investigations $[18,45]$ on ECAE $\mathrm{Cu}$ for up to $N=16$ via route $\mathrm{B}_{\mathrm{C}}$ have yielded similar results. Figure 2 shows that cell boundaries of lowangle configuration (i.e. LAGBs) are identified depending on the orientation of the adjacent cells either by clearly distinguishable high densities of dislocations and dislocation-debris or by fuzzy diffraction contrasts $(\boldsymbol{\nabla})$, while the sharper boundaries $(\boldsymbol{\nabla})$ (often also confined to grains where thickness fringes are visible), are considered to be HAGBs [41]. As seen in the coupled TEM images and SAD patterns after $N=1$ and 2 (Fig. 3 (a and b)), the microstructure is dominated by lamellar boundaries (LBs) oriented in the $\langle 110\rangle$ direction (along the trace of the $\{111\}$ plane),

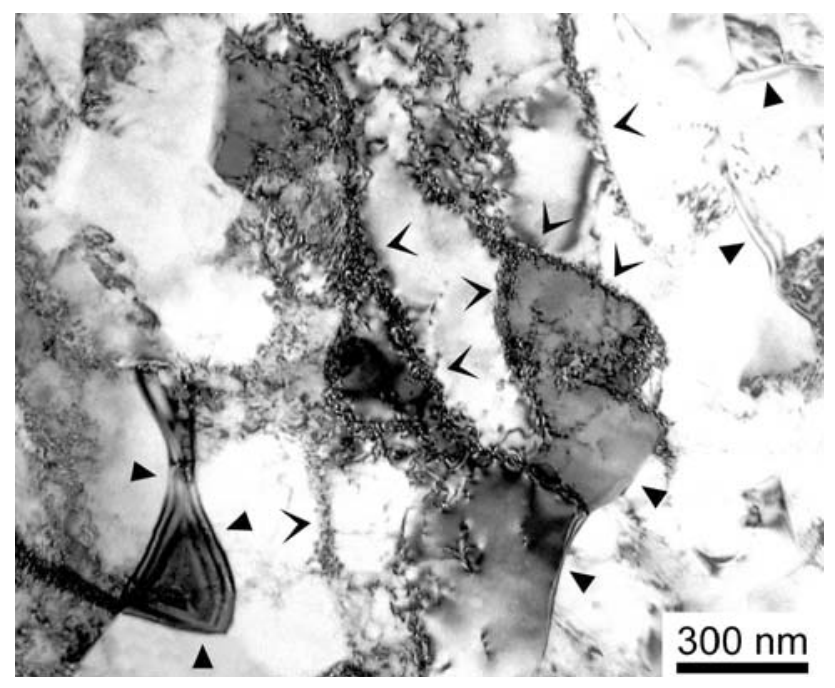

Fig. 2 TEM bright field (BF) image showing cell wall boundaries and/or subgrain boundaries ( $>$ ) and high angle grain boundaries $(\downarrow)$ in a specimen deformed up to $N=16$

resulting in a microstructure similar to rolling [32]. Dislocation cell boundaries are evident and as indicated by the SAD pattern mainly LAGBs are present. This observation has been reproduced more quantitatively by EBSD misorientation measurements (Fig. 4(a)).

After $N=4$ and 8 , the microstructure is inhomogeneous with respect to the various grain shapes. In some areas grains and subgrains are still elongated, while other areas are representative of equiaxed grain and substructures (Fig. 3 (c and d)). With greater $N$, the volume fraction of equiaxed microstructural features increases and the distribution of the diffraction spots is more uniform. This change in diffraction infers an increase in the misorientation (Fig. 4(b, c and d)), and subsequently recovery within the grains and their grain boundaries (Fig. 4(e and f)). An enhancement of recovered grain structures showing low dislocation densities in the interior and sharp grain boundaries with increasing $N$ is related to the higher effectiveness of dislocation annihilation due to an increase in the boundary misorientations. This in turn, is manifested by a decrease in the average boundary width from 52 to $34 \mathrm{~nm}$ and a decrease in the dislocation density $\left(6.9 \times 10^{13} \mathrm{~m}^{-2}\right)$ at $N=16$ after reaching a maximum $\left(3.2 \times 10^{14} \mathrm{~m}^{-2}\right)$ for $N=4$ (see ref. [18] for details). Furthermore, in agreement with [41] for route $C^{1}$, some larger (up to $500 \mathrm{~nm}$ ) grains characterised by sharp and straight boundaries were observed for samples with $N \geq 8$ and have been said to be precursors to recrystallised grains [18]. Also,

\footnotetext{
${ }^{1}$ They measured a volume fraction of $1.5 \%$ represented by dynamically recrystallised grains.
} 
Fig. 3 TEM BF images and SAD patterns of $\mathrm{Cu}$ samples subjected to $N=1$ (a), 2 (b), 4 (c), 8 (d), 12 (e) and 16 (f)
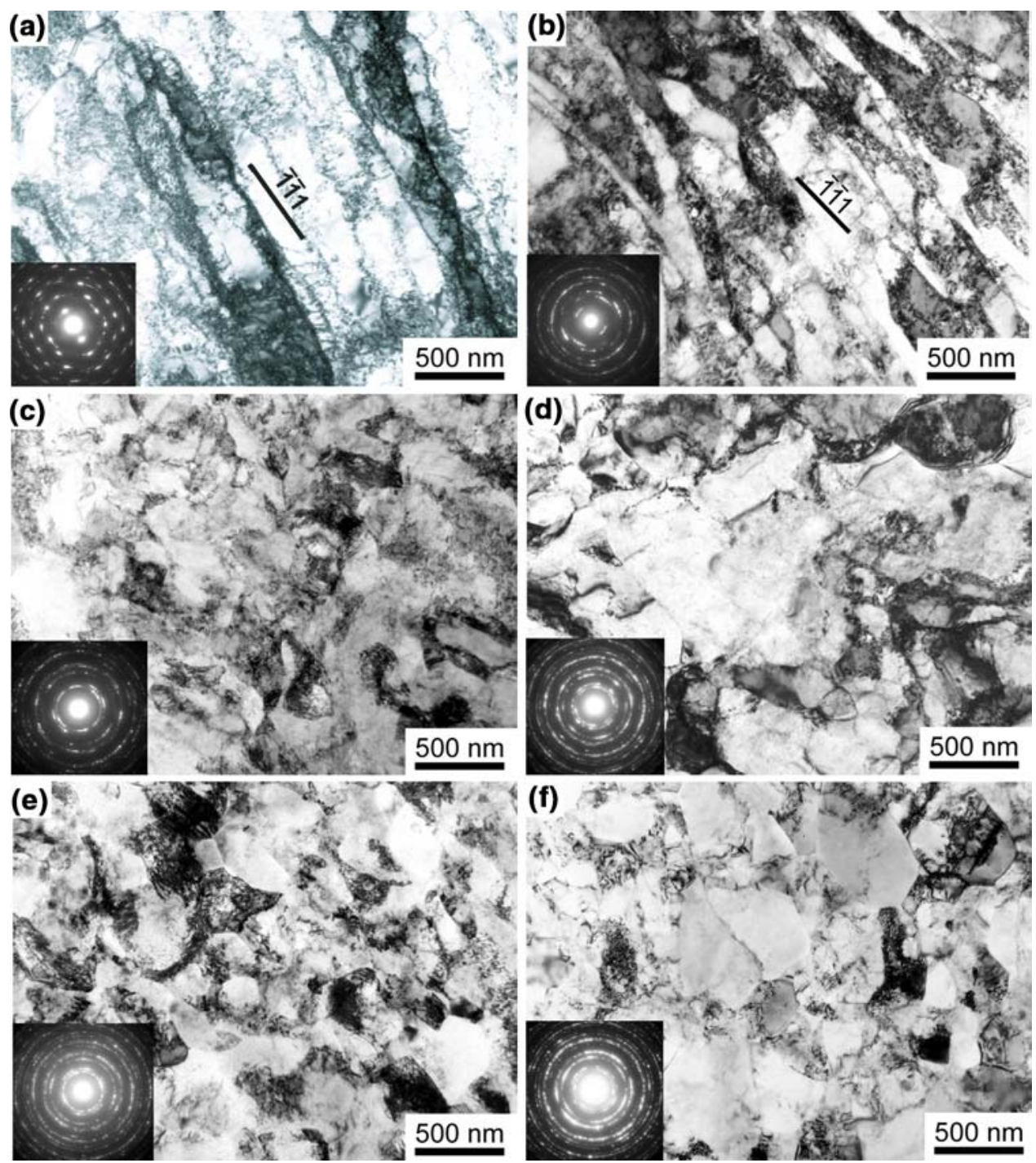

stacking fault tetrahedra and dislocation loops observed in larger grains containing only few lattice dislocations, lend further support to the occurrence of recovery processes (Fig. 4 (c and d) in ref. [18]).

To improve the statistics on the variation of grain size due to recovery and/or recrystallisation structures occurring during ECAE we performed EBSD measurements over a $40 \times 30 \mu \mathrm{m}$ area. Figure 5 shows a section taken from this larger EBSD map of the $N=16$ specimen. The black lines represent HAGBs, while thicker red lines correspond to $\Sigma 3$ boundaries. The few larger grains (up to $1 \mu \mathrm{m}$ in size) with a high abundance of $\Sigma 3$ boundaries are surrounded by smaller grains $\sim 170 \mathrm{~nm}$ in size. Over the entire map of $40 \times 30 \mu \mathrm{m}$ about $1-2 \%$ of the grains can be classed as recrystallised grains with a mean size of $1.0 \mu \mathrm{m}$, based upon the qualifying assumptions that: (i) the recrystallised grain size is 6 times larger than the mean subgrain size, (ii) a recrystallised grain is bounded by at least $10 \%$ HAGB and, (iii) that the image quality remains constant ${ }^{2}$. A similar observation of such grains of $1 \mu \mathrm{m}$ size with a volume fraction of $1.5 \%$ have recently been reported for a $\mathrm{Cu}$ specimen subjected to $N=8$ passes, route $\mathrm{B}_{\mathrm{C}}$ [46]. From the current standpoint, the processes that lead to the formation of such large grains requires further investigation. Thus, the nature of these recrystallised grains-whether they are of dynamic (i.e. during ECAE deformation) or static (i.e either upon removal of hydrostatic pressure conditions in the ECAE set-up at the end of a pass or during storage of specimens at RT) origin requires clarification. With specific regard to latter, it should be noted that the process of relaxation is assumed to

$\overline{2}$ With increasing fraction of recrystallised grains, the image quality is expected to improve. 
Fig. 4 Misorientation measurements of $\mathrm{Cu}$ after $N=$ (a) 1, (b) 4, (c) 8 and, (d) 16 passes (route $\mathrm{B}_{\mathrm{C}}$ )
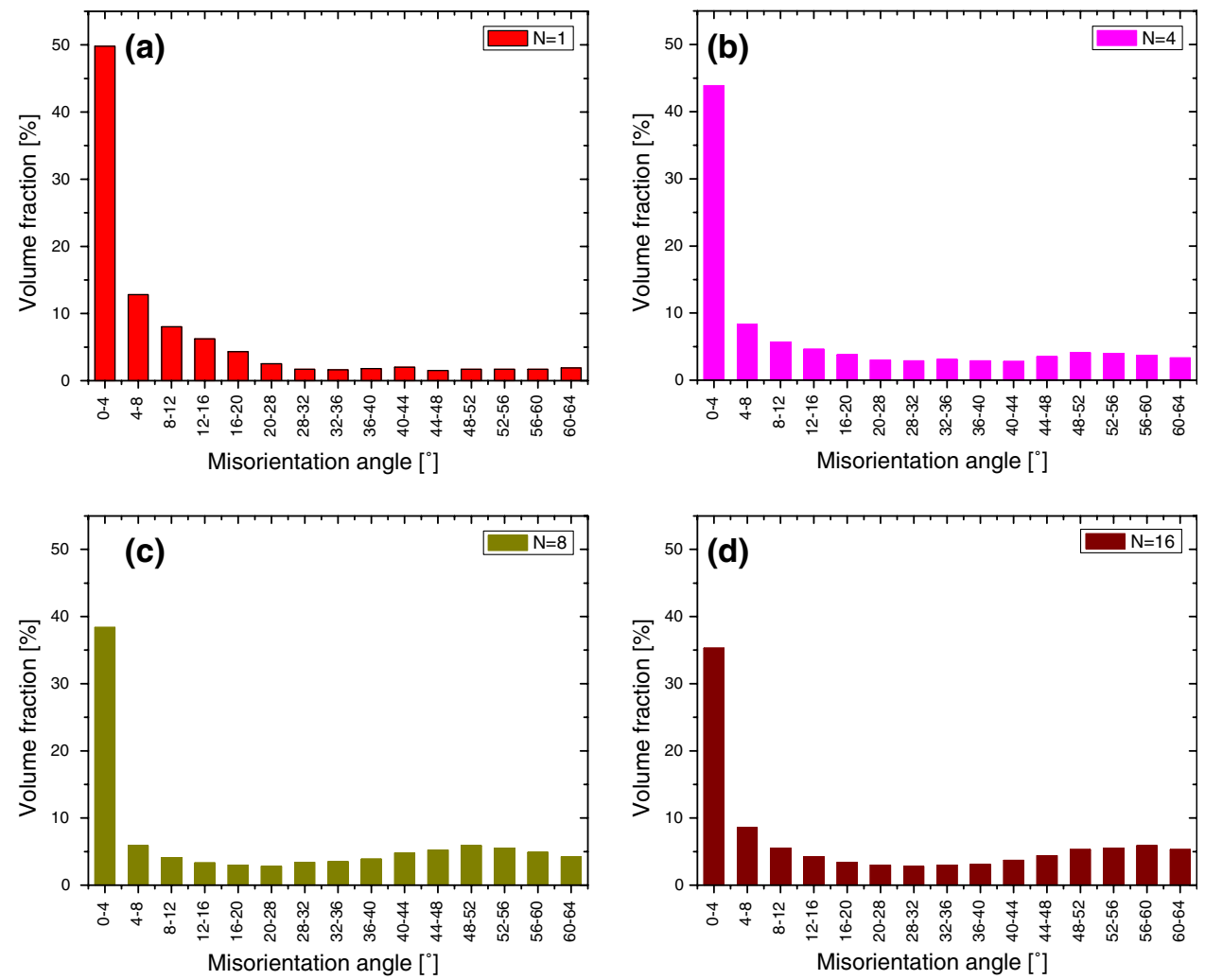

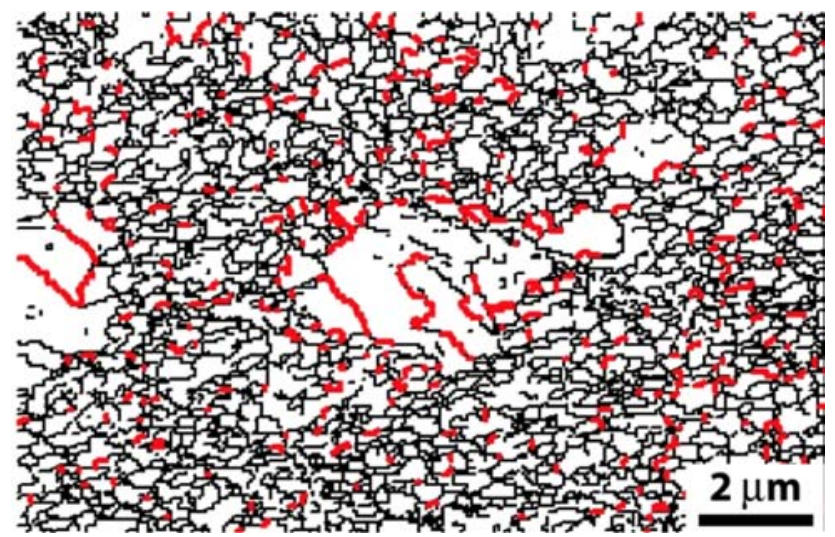

Fig. 5 EBSD map of a specimen subjected to $N=16$ passes. Black lines indicate high angle grain boundaries, red thicker lines correspond to $\Sigma 3$ boundaries

follow an Arrhenius-type law. Consequently, beyond a critical time period, no microstructural differences should be detectable after billet removal from the ECAE apparatus. To this end, TEM investigations on samples produced at varying time intervals spread out over a few weeks have also returned no discernable substructural differences.

Statistical TEM cell size measurements on our samples are also in qualitative agreement with results published on route $\mathrm{C}$ [36]. The cell size perpendicular to the dominant LBs reaches a minimum value of $\sim 170 \mathrm{~nm}$ after the first pass and remains roughly constant. However, our measurements also showed that the cell sizes parallel to the LBs decreases more gradually. It is important to note that this behaviour is quite different to ECAE Al, which shows an overall gradual decrease in grain size, a much larger mean grain size of $\sim 1 \mu \mathrm{m}$ and the appearance of a strongly recovered microstructure [47, 48]. This behaviour can be attributed to either the significantly higher homologous processing temperature of $\mathrm{Al}$ (the melting temperature $\left(T_{\mathrm{m}}\right)$ of $\mathrm{Cu}$ is $1357 \mathrm{~K}$ compared to $933 \mathrm{~K}$ for $\mathrm{Al}$ ) or explained by the larger stacking fault energy of $\mathrm{Al}$, which favours cross slip and dislocation climb, both effects instigating higher rates of recovery at a constant temperature.

\section{Twinning in ECAE Cu}

Several observations on heavily deformed $\mathrm{Cu}$ via ECAE or HPT (the latter yielding a grain size of about $\sim 100 \mathrm{~nm}$ due to the suppression of vacancy annihilation under hydrostatic pressure conditions [49]) have shown the presence of stacking faults and twins $[18,45,50-52]$. This is somewhat surprising since deformation twinning is not regarded as energetically favourable at low strain rates and ambient tempera- 
tures due to the many slip systems still able to operate in coarse-grained $\mathrm{Cu}[53,54]$. However, specific to coarse-grained $\mathrm{Cu}$, deformation twinning occurred after substantial strain hardening [55] and has been shown to become favourable once a critical dislocation density is reached [56]. Huang et al. [50] indicated that the twinning mechanism does change as a function of strain and/or grain size. After $N=1$, twins have been found in or at shear bands indicating that in areas where locally high strains are reached, deformation twins can be favoured over dislocation slip.

In apparent agreement with these observations, our EBSD experiments also revealed a higher density of $\Sigma 3$ boundaries at shear bands (see white lines in Fig. 6(a), indicated by the arrow). Note that $\Sigma 3$ boundaries can have different geometries and comprise, apart from symmetric tilt boundaries (i.e. coherent twin boundaries), incoherent twins $\left(\Sigma 3^{\prime \prime}\right)$ and stacking faults in fcc materials [57, 58]. Huang et al. [50] associated the occurrence of twins observed after $N=1$ with the pole mechanism, which nucleates from the dissociation of prismatic dislocations into partials and grows helically via climb of the Shockley partial dislocations [59]. At larger strains $\left(N \geq 16\right.$ route $\left.\mathrm{B}_{\mathrm{C}}\right)$, twins associated with the emission of partial dislocations from grain boundaries (as suggested by computer simulations [60] and experiments [61-64] on nanocrystalline (nc) fcc metals) were also observed by Huang et al. [50]. However, our results indicate that when compared with the total amount of boundaries, the fraction of $\Sigma 3$ boundaries remains low: which suggests that discussing twinning as a deformation mechanism in ECAE $\mathrm{Cu}$ is of comparatively minor importance. Figures 6(b and c) shows
EBSD maps of samples subjected to $N=4$ and 16 passes, where $\Sigma 3$ boundaries are rather widely distributed over the sample area. As shown in the close-up of the specimen subjected to $N=16$ (Fig. 6(d)), $\Sigma 3$ boundaries extend over entire grains, are sometimes interacting with subgrain boundaries and can be found in grains of smaller than $200 \mathrm{~nm}$ in size. TEM observations also reveal a similar picture. In Fig. 7(a and b), the TEM image of a large grain is shown wherein dislocations are moving from the left-hand grain boundary towards a boundary which forms ledges (probably due to stress incompatibility). These ledges associated with stacking faults and a high density of grain boundary dislocations resemble those typically related to the initiation of annealing twins at the ledges as suggested by the 'pop-out' mechanism, and where growth occurs via migration of the incoherent and more mobile $\Sigma 3$ boundaries [65]. In their model, Meyers and Murr [65] explain the driving force for the nucleation of twins by the reduction in dislocation density, which is again in agreement with our observation of lower dislocation densities in larger grains as those shown in Fig. 7. Here, a clearer identification of the nucleation mode (i.e. annealing or deformation) is not possible. In Fig. 7(c), two stacking faults are shown crossing an entire grain. Considering the observations made by TEM and EBSD, it is important to emphasise the difference in appearance between these twins and those associated with the large grain shown in Fig. 5. It is however interesting to note that $\Sigma 3$ boundaries also occur within the fine grained matrix (Fig. 5), which might suggest that these serve as nuclei for the growth of annealing twins. However, this caveat requires the
Fig. 6 EBSD maps of $N=1$ (a), $N=4$ (b) and $N=16$ $(\mathbf{c}+\mathbf{d})$. Grey, black and white lines correspond to subgrain, grain and $\Sigma 3$ boundaries, respectively. Figure $6(\mathrm{~d})$ is an enlarged area of Figure 6(c)
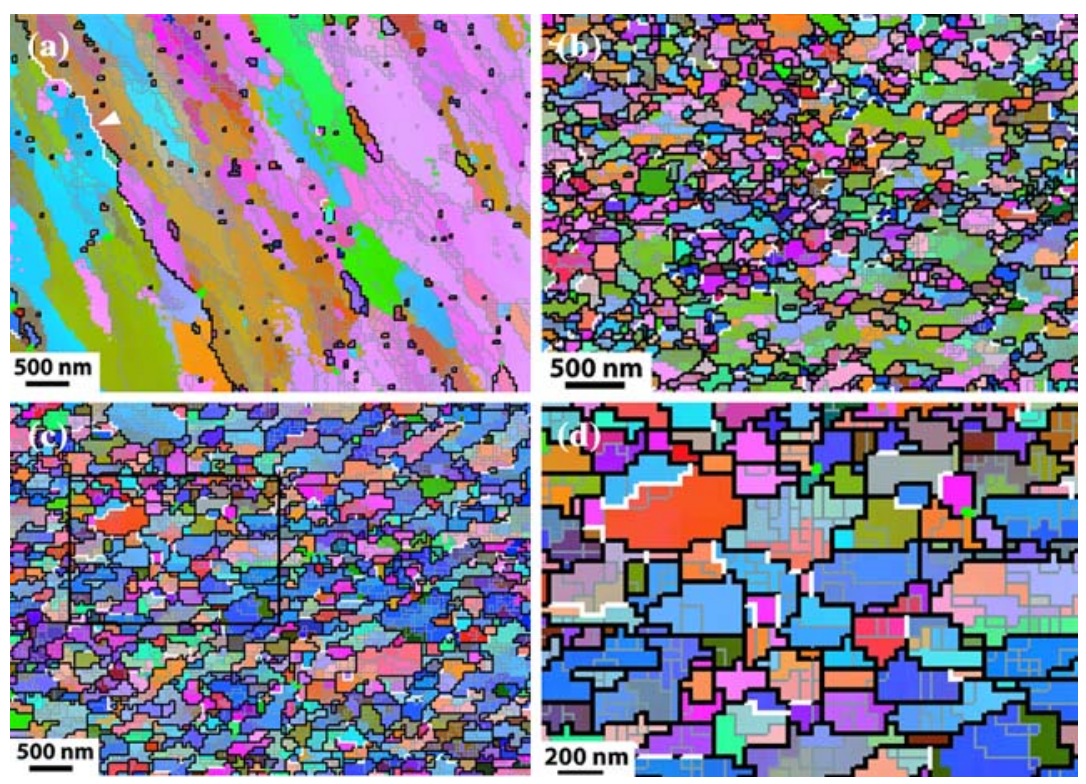
Fig. 7 Deformation structures of $\mathrm{Cu}$ specimens subjected to $N=8$ passes. (b) shows an enlarged area of (a)
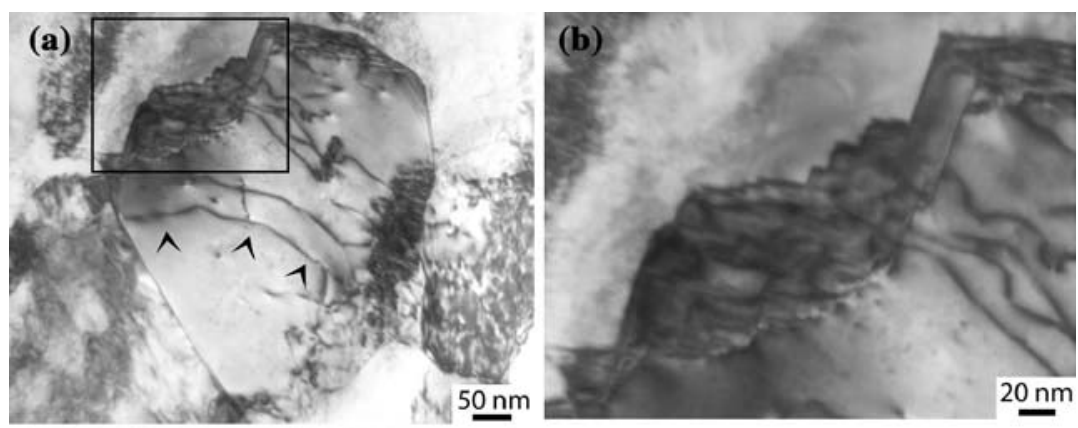

deformation and annealing twins to be crystallographically identical as they consist of stacking faults on consecutive $\{111\}$ planes [66].

\section{Texture evolution in ECAE-Cu}

Figure 8 shows the (111) experimental pole figure of the 0 -pass billet prior to ECAE. Similar to a previous study [67], this initial texture is weak and consists mainly of a $\langle 111\rangle+\langle 001\rangle$ duplex fiber with the fiber axis parallel to the billet longitudinal axis.

In order to evaluate textures developed during ECAE, a translation from the negative simple shear (SS) reference system (or $x^{\prime} y^{\prime} z$ system) to the sample coordinate system (or $x y z$ system) is accomplished by a

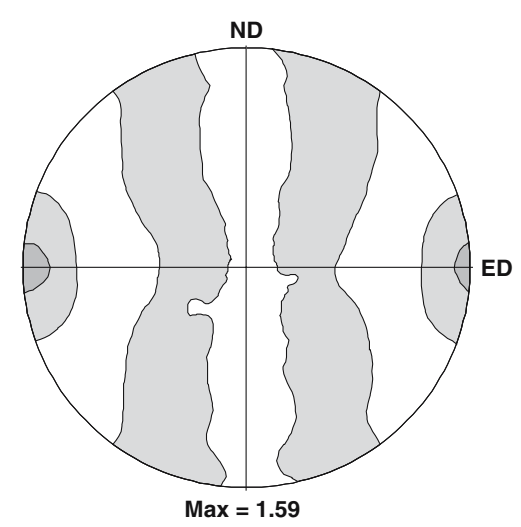

Fig. 8 (111) pole figure of the 0-pass starting texture for $\mathrm{Cu}$. The longitudinal axis of the billet is horizontal. Contour levels: $0.5 \times$ clockwise (CW)-rotation of $\theta=\Phi / 2=45^{\circ}$ about the $z$ axis. Li et al. [68] showed that ECAE specific orientations can be derived by increasing the $\varphi_{1}$ of ideal SS orientations by $\theta=45^{\circ}$ while the other two Euler angles $\left(\varphi\right.$ and $\left.\varphi_{2}\right)$ remain constant. The Euler angles are listed in Table 2. The symbols marked in the key (111) PF (Fig. 9(a)) represent these ideal ECAE orientations for fcc metals [69] that distribute themselves along two partial fibers running along: (i) $\{111\}$ planes with $\langle u v w\rangle$ directions or, (ii) $\{h k l\}$ planes with $\langle 110\rangle$ directions, counter-clockwise (CCW)-rotated by $\theta=45^{\circ}$ around the TD from the ND-plane and ED, respectively and are labelled using subscript $(\theta)$. They are designated as: (i) $\{111\}\langle u v w\rangle_{\theta}$ and, (ii) $\{h k l\}\langle 110\rangle_{\theta}$ type partial fibers, respectively.

As seen in Fig. 9(b), the 1-pass experimental pole figure contains dyadic symmetry and depicts an inversion center projected on to the $z$-plane. It consists of a partial $\langle 110\rangle_{\theta}$ fiber running from $C_{\theta}$ to $A_{\theta} / \bar{A}_{\theta}$ ('/ symbolises 'or') through $B_{\theta} / \bar{B}_{\theta}$ orientations and a partial $\{111\}_{\theta}$ fiber extending from $A_{1 \theta}^{*}$ to $A_{2 \theta}^{*}$ through $A_{\theta} / \bar{A}_{\theta}$. Relatively high orientation densities can be found near the $C_{\theta}$ and $A_{1 \theta}^{*}$ components. In reference [68] it is shown that the $A_{1 \theta}^{*}$ component is stronger than the $A_{2 \theta}^{*}$ component as a result of negative SS. Generally speaking, the present texture components after a single pass are closely aligned to the ideal ECAE orientations, which also correspond to the ideal simple shear textures obtained via torsion [70-72]. $N=2$ pass PFs (Fig. 10(a)) indicate that while the orientations remain distributed along the partials described above, there are some significant differences in terms of 
Table 2 Ideal orientations and fibers for fcc materials after a single pass $90^{\circ}$ ECAE

\begin{tabular}{|c|c|c|c|c|c|}
\hline \multirow[t]{2}{*}{ Notation } & \multicolumn{3}{|c|}{ Euler angles $\left(^{\circ}\right)$ for $\varphi_{2}=0^{\circ}$ and $45^{\circ}$ sections } & \multirow[t]{2}{*}{ Equivalent TD-rotation by $\theta=45^{\circ}$} & \multirow[t]{2}{*}{ Fiber Family } \\
\hline & $\varphi_{1}$ & $\varphi$ & $\varphi_{2}$ & & \\
\hline$A_{1 \theta}^{*}$ & $\begin{array}{l}80.3,260.3 \\
170.3,350.3\end{array}$ & $\begin{array}{l}45 \\
90\end{array}$ & $\begin{array}{l}0 \\
45\end{array}$ & $(111)[\overline{1} \overline{1} 2]_{\theta}$ & $\{111\}_{\theta}$ \\
\hline$A_{2 \theta}^{*}$ & $\begin{array}{l}9.7,189.7 \\
99.7,279.7\end{array}$ & $\begin{array}{l}45 \\
90\end{array}$ & $\begin{array}{l}0 \\
45\end{array}$ & $(111)[11 \overline{2}]_{\theta}$ & $\{111\}_{\theta}$ \\
\hline $\begin{array}{c}A_{\theta} \\
\bar{A}_{\theta} \\
B_{\theta} \\
\bar{B}_{\theta} \\
C_{\theta}\end{array}$ & $\begin{array}{l}45 \\
225 \\
45,165,285 \\
105,225,345 \\
135,315 \\
45,225\end{array}$ & $\begin{array}{l}35.3 \\
35.3 \\
54.7 \\
54.7 \\
45 \\
90\end{array}$ & $\begin{array}{l}45 \\
45 \\
45 \\
45 \\
0 \\
45\end{array}$ & $\begin{array}{l}(1 \overline{1} 1)[110]_{\theta} \\
(\overline{1} 1 \overline{1})[\overline{1} \overline{1} 0]_{\theta} \\
(1 \overline{1} 2)\left[\begin{array}{ll}11 & 1\end{array}\right]_{\theta} \\
(\overline{1} 12)\left[\begin{array}{lll}1 & 1 & 0\end{array}\right]_{\theta} \\
\left(\begin{array}{llll}0 & 0 & 1\end{array}\right)\left\langle\begin{array}{lll}1 & 1 & 0\rangle_{\theta}\end{array}\right.\end{array}$ & $\begin{array}{l}\{111\}_{\theta},\langle 110\rangle_{\theta} \\
\{111\}_{\theta},\langle 110\rangle_{\theta} \\
\langle 110\rangle_{\theta} \\
\langle 110\rangle_{\theta} \\
\langle 110\rangle_{\theta}\end{array}$ \\
\hline
\end{tabular}

orientation distribution and intensity when compared to their 1-pass counterparts (Fig. 9(b)). The nearmonoclinic symmetry of 1-pass ECAE is lost, the $C_{\theta}$, $A_{\theta}$ and $\bar{A}_{\theta}$ orientations have weakened, and the components near the $B_{\theta}$ and $\bar{B}_{\theta}$ orientations have strengthened. Overall, this leads to incomplete and non-uniform orientation densities along the fibers.

After $N=4$ (Fig. 10(b)), the incompleteness and non-uniformity of the fibers remain as orientation densities differ and also result in an overall reduction in the maximum texture intensity $(f(g))$. As a direct consequence of further processing, minor peaks belonging to retained components from previous passes are also observed. Compared to the 1 pass specimen, the end of $N=4$ passes results in significant weakening of intensities around the $A_{2 \theta}^{*}$ and $C_{\theta}$ components accompanied by the moderately stronger $A_{1 \theta}^{*}$ orientation. When comparing the relative strengths of orientation densities among the various components after $N=8$ (Fig. $10(\mathrm{c})$ ), the results are similar to $N=4$ with comparatively lesser $f(g)$ recorded for intensities around $A_{2 \theta}^{*}$ and $C_{\theta}$. However, despite the reproducibility in texture components, larger disparities do exist. In direct comparison to the $N=4$ condition,
$N=8$ resulted in a further strengthening of $A_{1 \theta}^{*}$ and $\bar{B}_{\theta}$ orientations. The most notable difference in terms of orientation densities between $N=4$ compared to $N=12$ and 16 (Fig. 10(d and e)) is that greater strain not only produces a net spread of orientation components but also results in a weakening of all ideal sheartype orientations in agreement with previous work [67, 72-74]. Interestingly and common to $N=4,8,12$ and 16 pass conditions, the re-appearance of weak texture components of the initial $N=0$ texture reflects glidereversal effects that return part of the substructure into an equiaxed configuration.

It must be noted that the weakening trend of $f(g)$ is in contradiction with other investigations $[75,76]$ that postulate an increase in texture strengthening with greater imparted strain. Mainly, these disparities allude to the heterogeneity of the as-deformed billet due to varying friction conditions at the billet-die interface $[69,73,77]$ and also the degree of difficulty in locating the exact center of the billet stable length (from where the ED-plane sample is cut) for equivalent texture scans with increasing $N$. In addition, differences such as: (i) the starting texture of the material at $N=0$ [74] and, (ii) the area of the sample over which the texture
Fig. 9 (a) (111) pole figure showing ideal orientations (symbols) and partial fibers (thick solid lines) after a single pass of ECAE deformation for fcc materials using a $\Phi=90^{\circ}$ die [67]. (b) (111) pole figure of the experimental textures after $N=1$. Contour levels: $0.5 \times$

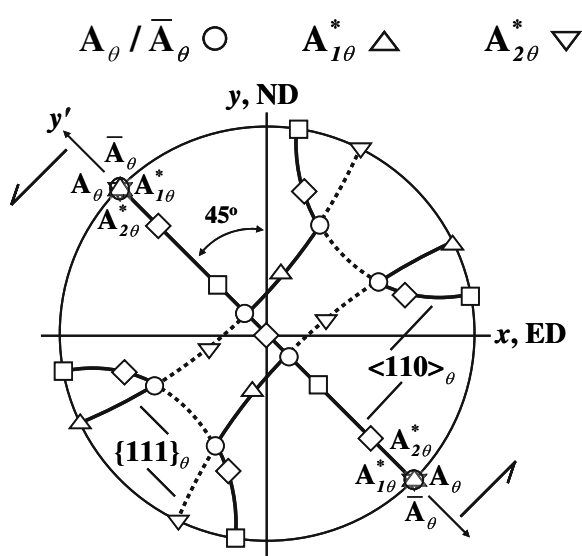

(a)

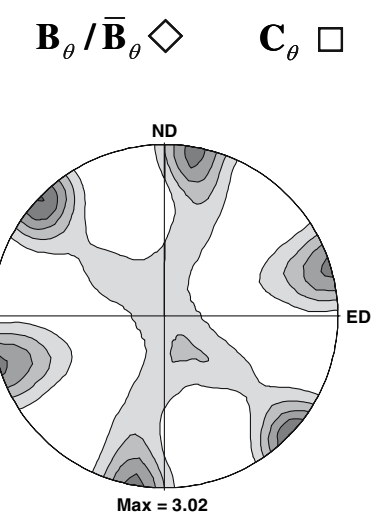

(b) 
Fig. 10 (111) pole figures of the experimental textures after $N=$ (a) 2, (b) 4, (c) 8, (d) 12 and, (e) 16 passes, route $\mathrm{B}_{\mathrm{C}}$ ECAE. Contour levels: $0.5 \times$

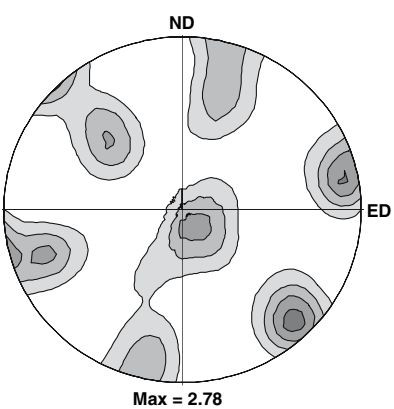

(a)

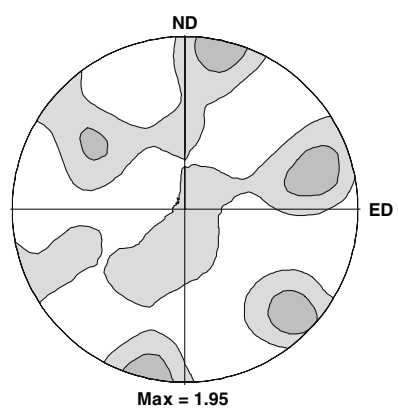

(d)

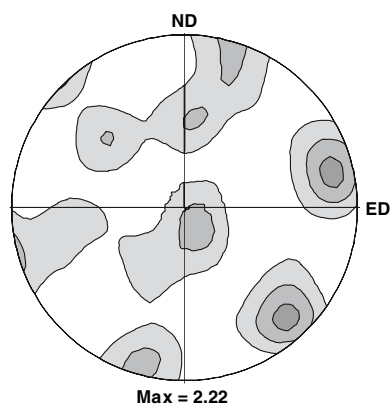

(b)

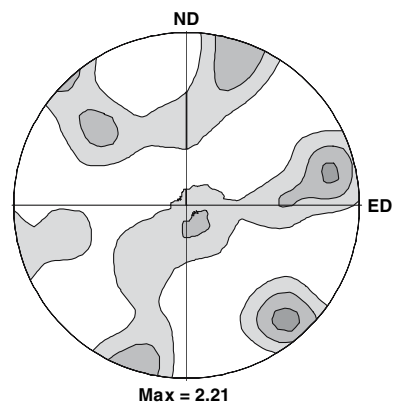

(e)

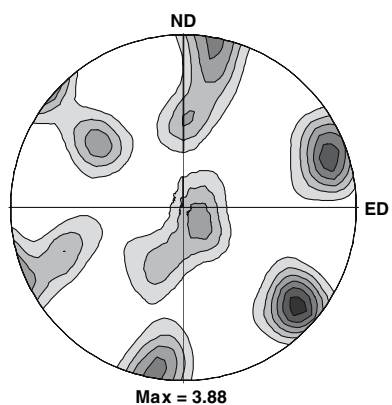

(c) scan is performed [67, 75] also mean that direct comparisons of our texture results with those found in literature must be made with care.

\section{Mechanical properties of ECAE-Cu}

During ECAE processing, accurate stress and strain levels cannot be quantified due the operation of friction forces at the billet-die interface. Consequently, variations in material properties as a function of the employed strain-path changes between successive passes cannot be properly evaluated. From strain reversal experiments, it is well known that a change in the strain path produces a change in the internal stress-generally described as the Bauschinger effect. In cases, where the reloading stress exceeds the pre-deformation stress level, a dissolution of the previous cell structures and a untangling of formerly strong dislocation arrangements within the walls is accompanied by a stagnation of the strain hardening-before a steady state is re-established after few percentage of reloading strains ([13] and references therein). Therefore, if the deformation behaviour of prestrained materials is being evaluated, it is important to account for such effects.

\section{Tensile testing}

Figure 11 shows the true strain true stress curves in (a) tension and, (b) compression derived from engineering stress-strain curves using standard equations. Alternatively, Fig. 12 shows a quantitative summary of tensile test data after $N=0,1,4,8,12$ and 16 passes represented in terms of yield and ultimate tensile strength (YS and UTS), uniform and total strain before failure. The annealed $N=0$ specimen shows a low yield strength, followed by a long period of uniform strain hardening and a short post-necking elongation. On the other hand, ECAE-Cu specimens show significantly higher yield strengths, followed by a short amount of uniform elongation with steep hardening and a larger post-necking elongation. Note that the true stress true strain curves cannot capture the effective stress and strain in the necking part of the sample after having reached the UTS. The YS and UTS increase up to $N=4$ and decrease moderately thereafter. A similar observation has been made on $\mathrm{Cu}$ deformed via route $\mathrm{C}$ up to $N=16$ using a $\Phi=120^{\circ}$ die angle [78]. Generally, tensile tests indicate only a very small increase in uniform plastic elongation and a total elongation $\left(\varepsilon_{\text {tot }}\right)$ below $10 \%$ for all passes. These values are within the range prescribed by [79].

Slightly longer post-necking elongation values, but still much larger than the uniform strain, have been recently reported for specimens deformed for $N=16$ and 20 via route $\mathrm{B}_{\mathrm{C}}\left(\varepsilon_{\mathrm{tot}} \sim 15 \%\right)$ and for $N=2$ to 4 via route $\mathrm{C}\left(\varepsilon_{\mathrm{tot}} \sim 17-19 \%\right)$ [37, 80-82]. Yet, significantly larger total elongation has been reported for higher numbers of passes using route $\mathrm{B}_{\mathrm{C}}$ [83]. Recently, a total elongation value of $\varepsilon_{\text {tot }} \sim 35 \%$ (which exceeds that 

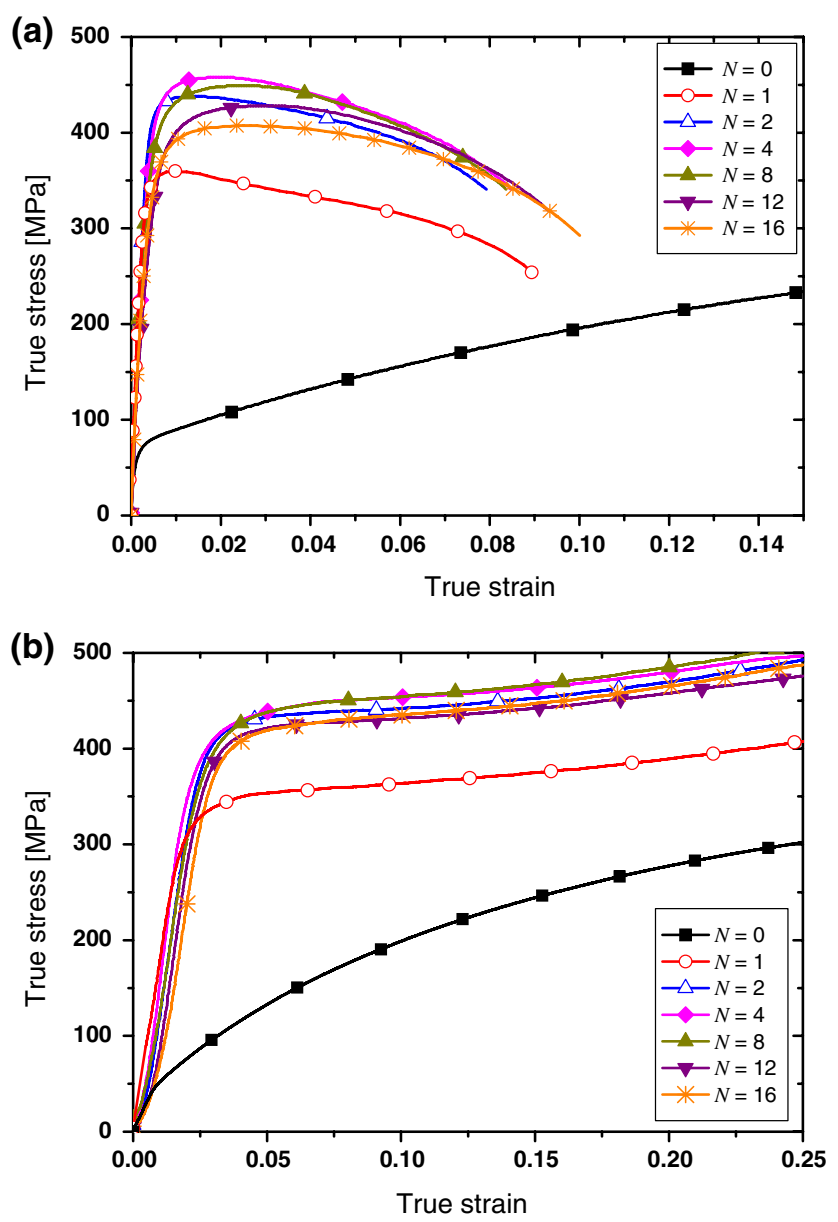

Fig. 11 Stress-strain curves for 0 to 16 passes in tension (a) and compression (b)

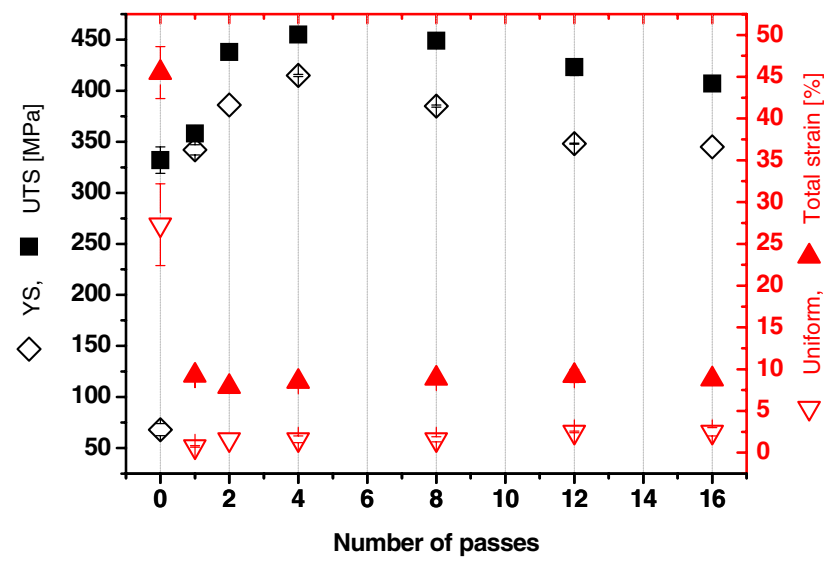

Fig. 12 Tensile test data of $\mathrm{Cu}$ processed up to $N=16$ passes for the yield strength (YS), ultimate tensile strength (UTS) and uniform and total elongation

of the annealed $N=0$ sample) was presented for $\mathrm{Cu}$ samples subjected to routes $\mathrm{C}$ and $\mathrm{E}$ for $N=8$ and 16 passes processed in a $\Phi=120^{\circ}$ angle die [84]. Since the tensile sample dimensions in these results are not indicative of any consistent size effect, other reasons have to be considered to explain the measured differences in total and/or uniform elongation. Note that the UTS for the tensile strains given in [37, 80-84] are all within the same range as measured here, indicating that the enhanced strain is not due to a larger grain size.

Wang and Ma [40] suggested that an increase in the strain rate sensitivity (SRS) would be one way to improve the tensile ductility as superplastically deformed materials have typical SRS values that range between 0.3 and 0.8. Earlier, such an explanation was also given by Valiev et al. [83] for explaining the high tensile strength of their ECAE $\mathrm{Cu}$ samples deformed at RT [83]. However, our data extracted from strain rate jump tests in compression shown in Table 3 (also plotted in [85]), indicate that the SRS value saturates at $\sim 0.02$ and is in agreement with the values given in [79] where smaller strain rate steps in-between the jumps had been used. It should be noted that such low values of SRS are not sufficient to delay deformation instability (and consequent necking) according to Hart's criterion [86]. As pointed out by Wang and Ma, only if the strain rate is sufficiently low $\left(\sim 10^{-6} \mathrm{~s}^{-1}\right)$ and enough time is given for the operation of diffusional mechanisms-will an increase in the SRS occur and produce an observable increase in the uniform elongation [40].

It has also been suggested that increasing the percentage volume fraction of HAGBs proves beneficial to the uniform elongation [83, 87]. A recent study on a $\mathrm{Cu}-0.36 \mathrm{Cr}$ alloy deformed by route $\mathrm{A}$ up to $N=16$, exhibits uniform and total elongations of $\sim 10 \%$ and $\sim 23 \%$ respectively, and a UTS of $410 \mathrm{MPa}$. On the other hand, a sample deformed up to $N=16$ via an alternated route $\mathrm{C}$ and A type processing schedule, showed uniform and total elongations of $\sim 4 \%$ and $\sim 20 \%$, respectively and a UTS of $435 \mathrm{MPa}$. EBSD studies on these samples indicate the prevalence of a greater fraction of HAGBs $\left(f_{\mathrm{HAGB}}\right.$ $\sim 67-75 \%$ ) for the sample with greater uniform strain compared to the sample $\left(f_{\mathrm{HAGB}} \sim 52-63 \%\right)$ exhibiting less uniform strain [88]. Qualitatively, this is in agreement with our observations wherein a lower fraction of HAGB and a lower uniform elongation was measured for samples at $N \leq 4$ compared to those deformed for $N>4$. It had been suggested [83, 87] that a microstructure comprising mainly HAGBs would promote deformation mechanisms other than those mediated by dislocations. But taking the low magnitude of measured SRS values into consideration (see Table 3), mechanisms which are solely dependent on diffusion process are of minor importance. However, diffusion phenomena are indirectly connected to the 
Table 3 Compressive yield strength and strain rate sensitivity $(m)$ of $\mathrm{Cu}$ specimens subjected to $N=1$ to 16 passes ECAE (route $\mathrm{B}_{\mathrm{C}}$ )

\begin{tabular}{|c|c|c|c|c|c|c|}
\hline \multirow[t]{2}{*}{ Mechanical Property } & \multicolumn{6}{|c|}{ Number of passes $(N)$} \\
\hline & 0 & 1 & 4 & 8 & 12 & 16 \\
\hline$\sigma_{y}(0.2 \%)[\mathrm{MPa}]$ & 60 & & 324 & 369 & 332 & 346 \\
\hline$m$ & $0.007 \pm 0.001$ & $0.009 \pm 0.003$ & $0.015 \pm 0.005$ & $0.018 \pm 0.003$ & $0.021 \pm 0.002$ & $0.022 \pm 0.002$ \\
\hline
\end{tabular}

major operative mechanism-which is characterised by dislocation glide through the crystals and their accommodation and evolution within the cell wall structure. The possibility of texture effects (whereby an increase in ductility via dislocation slip along more preferential orientations can be induced) is also negated as the present texture results show a generally route-specific and reproducible trend of preferred orientations with increasing $N$.

In order to further clarify this question, we have also carried out detailed TEM and XRD analysis on the evolution of the deformation microstructure with respect to $N$ [18]. With increasing $N$ (up to $N=16$ ), a decrease in the wall thickness and dislocation density within the subgrains occurs. All the while, the cell or subgrain size remains roughly constant. These findings are in agreement with a corresponding decrease in the microstrain measured by XRD (see Ref. [18] for more details). This would strongly suggest that the mean free path of dislocations increases in samples processed beyond $N \geq 4$. It can be therefore suggested that an increased volume fraction of HAGBs (which themselves are known to be effective sinks for incoming lattice dislocations), and a lower dislocation density within subgrains (and hence, a greater mean free path of dislocations) help reduce sources of plastic instability such as stress concentrations and thereby makes possible an increase in percent elongation. Apropos to the agreement between microstructural analysis of the ECAE material performed before mechanical testing and consequent mechanical behaviour during testing, it can be assumed that microstructural changes occurring during the few percentage of strain reached during tensile testing are of minor importance for the interpretation of the stress-strain curves.

It should also be noted that while the above mechanisms could explain the mechanical behaviour of SPD-UFG materials to a very large extent, another source of inconsistency in the available literature data could originate from a higher material-specific sensitivity to external flaws, a phenomena which is also known to affect nc metals [89]. Thus, further experimental results are still needed to resolve these differences and/or ambiguities.
Strain hardening stages III, IV and V measured in compression

Unlike tensile tests, uniaxial compression tests do not suffer from necking instability and can be used to describe the strain hardening behaviour. In the following passages, the hardening behaviour of the ECAE deformed samples is described in the classical context of strain hardening theory reviewed in [1-3]. In doing so, the effects of strain path changes from simple shear (or, ideal ECAE) to pure shear (compression) are neglected. Nevertheless, this description showed usefulness in describing the hardening behaviour as a function of the number of passes and is in agreement with the general microstructural and hardening response for stages II-V.

In Fig. 13, the strain hardening versus the shear stress of samples up to $N=1$ to 16 is shown. The shear stress has been calculated by dividing the true stress by a constant Taylor factor $\left(M_{T}\right)$ of 3.06 , which corresponds to the value of a non-textured sample ${ }^{3}$. The shear strain hardening rate results from the conversion of the true stress and strain via $\left(\frac{\partial \sigma}{\partial \varepsilon}\right) \cdot\left(\frac{1}{M_{T}^{2}}\right)=\partial \tau / \partial \gamma$, where $\tau$ is the shear stress and $\gamma$ the shear strain. By linear extrapolation of the steep negative slope, a saturation stress $\left(\tau_{\text {IIIs }}\right)$ for stage III hardening can be estimated. This value reaches a maximum between $N=4$ to 8 (Fig. 13(a) and Table 4). It is also important to note that despite reaching stages IV and $\mathrm{V}$ hardening during ECAE, a clear indication of the re-occurrence of stage III during post-ECAE compression straining is visible in the hardening curves [85]. This observation has also been recently recognised for ECAE Ni [90].

During stage III, a net increase in the dislocation density is still prevalent, which when contrasted with stage II is less dominant and bears a dislocation annihilation component [1-3]. As compared to stage II, stage III is also commonly described by a higher strain rate and temperature sensitivity which increases with increasing stress and is associated with processes

\footnotetext{
${ }^{3}$ Possible effects on the shear stress due to changes in the Taylor factor during straining have been neglected.
} 

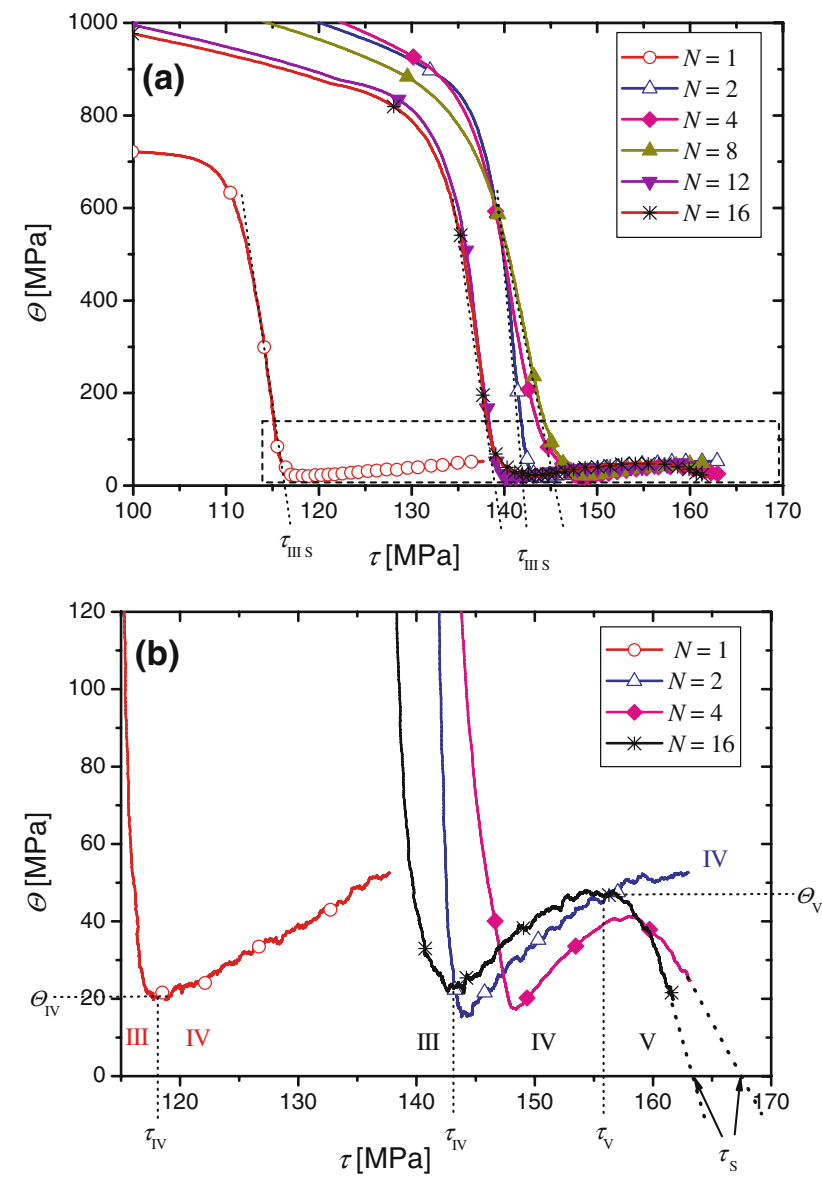

Fig. 13 Strain hardening behaviour of $\mathrm{Cu}$ processed by ECAE for $N=1-16$ passes. In (b) a close-up of (a) is shown

of dynamic recovery [1-3, 91]. During stage IV, the annihilation rate of dislocations becomes as strong as the storage rate so the hardening capacity declines and leads to a steady SRS state for a corresponding change in stress [3, 91]. In agreement with the description of stages III and IV, we also observe an increase in the SRS with increasing stress in the one pass specimen followed by a plateau of the SRS level (see Fig. 6 in ref. [85]) measured in the two pass specimen. In Fig. 13(b), a further change in the slope after stage IV can be observed for the specimens subjected to $N \geq 4$ and is denoted as stage $V$. This stage shows a decrease in $\Theta_{\mathrm{V}}$ values with stress and leads to a final saturation stress $\left(\tau_{s}\right)$ before friction and barrelling effects negate it at large compression strains. However, in the case of multi-pass ECAE, the dependency of the SRS on the stress deviates from the classically described mechanisms ascribed to stage $\mathrm{V}$, where an increase in SRS values with increasing stress and strain should be observed [91]. Conversely, our results for $N \geq 4$ show a decrease in the SRS with increasing stress and strain (Figs. 5 and 6 in ref. [85]). This behaviour linked to the saturation limit reached in terms of accumulated stress and dislocation density for $N \geq 4$ can be associated with the change in the strain path from ECAE route $\mathrm{B}_{\mathrm{C}}$, to compression which causes a destruction and reorganisation of the microstructure: $20-30 \%$ larger cell wall sizes have been measured for the compressed $N=4$ samples as compared to non-compressed $N=4$ samples, while for $N=16$ pass samples no clear differences in cell size have been observed between compressed and un-compressed samples. Recovered grains with sharp grain boundaries and dislocation-free interiors often observed in the un-compressed $N=16$ samples are not present after compression testing to $40 \%$, but exchanged by grains which are decorated with a new dislocation structure (see Fig. 4 in ref. [85]). Similar microstructural observations in strain reversal experiments are also associated with the Bauschinger effect. According to these observations, it is currently not clear how far the stage V hardening observed in Fig. 13 is influenced by the change in the strain path.

Conversely, as a change in the stress causes a corresponding change in the SRS, the apparent activation

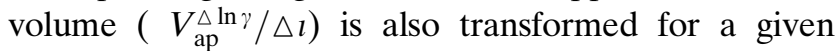
change in the hardening stage (see Fig. 7 in [85]). (see Fig. 7 in [85]). For $N>4$, activation volumes between 48 and $110 \cdot b^{3}(b$ is the Burgers Vector) have been measured with lowest values reached at very low strain rates, which are achieved in relaxation tests (for further details, see [85]). These values are also in agreement with those presented recently by Wei et al. [92]. Separating the effective activation volume into its constituents $V_{\text {eff }}=b \cdot x \cdot l$, (with $x$ being roughly equal $b$ ), a length scale $(l)$ of $\sim 15-30 \mathrm{~nm}$ results. This length scale is in the same range as deduced from our TEM analysis of the dislocation density within cell walls $\left(\rho_{\text {wall }} \sim 1.9 \times 10^{15} \mathrm{~m}^{-2}\right.$ [18]) if it is assumed that $l_{\text {TEM }} \sim \frac{1}{\sqrt{\rho_{\text {wall }}}}$. This gives credence to the assumption that the rate controlling mechanism in ECAE $\mathrm{Cu}$ at higher $N(\geq 8)$ is the interaction of lattice dislocations with cell wall or subgrain boundaries as also stated by $[92,93]$.

\section{Summary}

This work summarises our current understanding of the microstructural evolution and the mechanical behaviour of ECAE pre-deformed $\mathrm{Cu}$ via route $\mathrm{B}_{\mathrm{C}}$. While good agreement on the sub-grain/grain size and shape as a function of number of passes $(N)$ results from a comparison with available literature values, a less consistent picture can be deduced from misorientation measurements. Our results performed by electron backscatter diffraction (EBSD) indicate an increase in 
the amount of HAGBs with increasing $N$, which saturates at about $50 \%$. In agreement with literature an increase in the amount of $\Sigma 3$ boundaries, stacking faults, recovered or even partially recrystallised grains and decrease in boundary width with increasing $N$ is observed. Consistent with previous texture work a spread in the texture components away from the ideal simple shear components is observed with greater $N$.

Upon comparing with available literature on the mechanical behaviour of ECAE $\mathrm{Cu}$ good agreement has been found in terms of maximum yield and tensile stress reached. In this study a softening after $N=8$, in agreement with microstructural evolution is observed. With respect to the maximum tensile strain reached before failure in ECAE $\mathrm{Cu}$ larger disparities were found, which might be associated with testing conditions and external flaws. Here, total elongations do not exceed $10 \%$ strain for all passes, but do show a slight increase in uniform elongation for greater $N$. Despite the large amount of pre-strain imparted via ECAE, the strain hardening measured during compression tests indicates a recovery of stage III, which is followed by stage IV on further deformation. For samples processed to higher $N$, a hardening behaviour associated with stage $\mathrm{V}$ is also observed. Strain rate sensitivity values of the order of 0.02 and activation volume estimates, which yield a length scale of the same order as deduced from dislocation spacings in the cell wall boundaries suggest that the deformation kinetics are dictated by the interaction of lattice dislocations with the boundaries.

Acknowledgements Mrs. C. Gu is kindly acknowledged for assistance in texture measurements. This work was supported by the Swiss National Science Foundation, Grant \# 200021-105647 (FHDT), Monash International Post-Graduate Research Scholarship (AAG) and by the Australian Research Council Discovery Project, DP0557255 (CHJD, EVP).

\section{References}

1. Sevillano JG, Van Houtte P, Aernoudt E (1981) Prog Mater Sci 25:69

2. Nes E (1998) Prog Mater Sci 41:129

3. Kocks UF, Mecking H (2003) Prog Mater Sci 48:171

4. Valiev RZ, Islamgaliev RK, Alexandrov IV (2000) Prog Mater Sci 45:103

5. Segal VM, Reznikov VI, Drobyshevskiy AE, Kopylov VI (1981) Russian Metallurgy (Engl Transl) 1:115

6. Segal VM (1995) Mater Sci Eng A 197:157

7. Zhorin VA, Shashkin DP, Yenikoponyan NS (1984) DAN SSSR 278:144

8. Kuznetsov RI, Bykov VI, Chernyshov VP, Pilyugin VP, Yefremov NA, Posheyev VV (1985) Sverdlovsk, IFM UNTS RAN, 1985, Preprint 4/85 (in Russian)
9. Bridgman PW (1952) McGraw-Hill, New York (Reprinted by Harvard University Press, Cambridge, Mass., USA (1964))

10. Birringer R, Gleiter H, Klein H-P, Marquardt P (1984) Phys Lett A 102:365

11. Gleiter H (1989) Prog Mater Sci 33:223

12. Lowe TC (2006) Mater Sci Eng 355:503-504

13. Iwahashi Y, Horita Z, Nemoto M, Langdon TG (1998) Acta Mater 46:3317

14. Ferrasse S, Segal VM, Hartwig KT, Goforth RE (1997) Metall Mater Trans A 28:1047

15. Furukawa M, Iwahashi Y, Horita Z, Nemoto M, Langdon TG (1998) Mater Sci Eng A 257:328

16. Lapovok RYe (2005) J Mater Sci 40:341

17. Bowen JR, Gholinia A, Roberts SM, Prangnell PB (2000) Mater Sci Eng A 287:87

18. Dalla Torre FH, Lapovok R, Sandlin J, Thompson PF, Davies CHJ, Pereloma EV (2004) Acta Mater 52:4819

19. Humphreys FJ (2001) J Mater Sci 36:3833

20. Bowen JR, Mishin OV, Prangnell PB, Juul Jensen D (2002) Scripta Mater 47:289

21. Bunge H-J, Texture analysis in materials science: mathematical methods, Butterworth \& Co., 1st ed., Berlin (1982)

22. Valiev RZ, Krasilnikov NA, Tzenev NK (1991) Mater Sci Eng A 137:35

23. Valiev RZ, Mulyukov RR, Ovchinnikov VV (1990) Phil Mag Lett 62:253

24. Valiev RZ, Kozlov EV, Mulyukov RR (1993) Mater Sci Eng A $168: 141$

25. Valiev RZ, Mulyukov RR, Ovchinnikov VV, Shabashov VA (1991) Scripta Metall Mater 25:2717

26. Valiev RZ, Korznikova GF, Mulyukov KY, Mishra RS, Mukherjee AK (1997) Phil Mag B 75:803

27. Valiev RZ, Kozlov EV, Ivanov YuF, Lian J, Nazarov AA, Baudelet B (1994) Acta Metall Mater 42:2467

28. Mishin OV, Gottstein G (1998) Philos Mag A 78:373

29. Mishin OV, Juul Jensen D, Hansen N (2000) In: Hansen N, Huang X, Juul Jensen D (eds) Proc 21nd Ris $\varnothing$ Internat Symp Mater Sci: Recrystallisation-Fundamental Aspects and Relations to Deformation Microstructure. National Laboratory, Roskilde, Denmark, p 445

30. Mishin OV, Juul Jensen D, Hansen N (2003) Mater Sci Eng A. $342: 320$

31. Agnew SR (1998) PhD thesis, Northwestern University

32. Hughes DA, Hansen N (2000) Acta Mater 48:2985

33. Mishin OV, Huang X, Brown JR, Juul Jensen D (2001) In: Hansen N, Huang X, Juul Jensen D (eds) Proc 22nd Ris $\varnothing$ Internat. Symp. Mater. Sci.: Recrystallisation-Fundamental Aspects and Relations to Deformation Microstructure. National Laboratory, Roskilde, Denmark, p 335

34. Iwahashi Y, Horita Z, Nemoto M, Langdon TG (1997) Acta Mater 45:4733

35. Komura S, Horita Z, Nemoto M, Langdon TG (1999) J Mater Res 14:4044

36. Baik SC, Hellmig RJ, Estrin Y, Kim HS, Metallkd Z (2003) 94:759

37. Vinogradov A, Hashimoto S, Patlan V, Kitagawa K (2001) Mater Sci Eng A 862:319

38. Mingler B, Karnthaler HP, Zehetbauer M, Valiev RZ (2001) Mater Sci Eng A 242:319

39. Höppel HW, Zhou ZM, Mughrabi H, Valiev RZ (2002) Philos Mag A 82:1781

40. Wang YM, Ma E (2004) Acta Mater 52:1699

41. Huang WH, Yu CY, Kao PW, Chang CP (2004) Mater Sci Eng A 366:221 
42. Wu SD, Wang ZG, Jiang CB, Li GY, Alexandrov IV, Valiev RZ (2004) Mater Sci Eng A 560:387

43. Han S, Lim C, Kim C, Kim S (2005) Metall Mater Trans A 36:467

44. Vinogradov A, Suzuki T, Hashimoto S, Kitagawa K, Kuznetsov A, Dobatkin S (2006) Mater Sci For 971:503

45. Dalla Torre FH, Gazder AA, Gu CF, Davies CHJ, Pereloma EV, Met Mater Trans A (accepted for publication)

46. Etter AL, Solas D, Baudin T, Penelle R (2005) Mater Sci For 845:495

47. Baik SC, Estrin Y, Kim HS, Hellmig RJ (2003) Mater Sci Eng A 351:86

48. Chang CP, Sun PL, Kao PW (2000) Acta Mater 48:3377

49. Zehetbauer MJ, Steiner G, Schafler E, Korznikov A, Korznikova E (2006) Mater Sci For 57:503

50. Huang CX, Wang K, Wu SD, Zhang ZF, Li GY, Li SX (2006) Acta Mater 54:655

51. Liao XZ, Zhao YH, Srinivasan SG, Zhu YT, Valiev RZ, Gunderov DV (2004) Appl Phys Lett 84:592

52. Liao XZ, Zhao YH, Zhu YT, Valiev RZ, Gunderov DV (2004) J Appl Phys 96:636

53. Meyers MA, Vöhringer O, Lubarda VA (2001) Acta Mater 49:4025

54. Meyers MA, Andrade RU, Chokshi HA (1995) Metall Mater Trans A 26:2881

55. Christian JW, Mahajan S (1995) Prog Mater Sci 39:1

56. El-Danaf E, Kalidindi SR, Doherty RD (1999) Metall Mater Trans A 30:1223

57. Randle V (2004) Acta Mater 52:4067

58. Sutton AP, Balluffi RW (1996) Interfaces in crystalline materials. Oxford Science Publications, Clarendon Press, p 305

59. Venables JA (1961) Philos Mag 6:379

60. Yamakov V, Wolf D, Phillpot SR, Mukherjee AK, Gleiter H (2002) Nature Mater 1:45

61. Chen MW, Ma E, Hemker KJ, Sheng HW, Wang YM, Cheng XM (2003) Science 300:1275

62. Liao XZ, Zhou F, Lavernia EJ, Srinivasan SG, Baskes MI, He DW, Zhu YT (2003) Appl Phys Lett 83:632

63. Liao XZ, Zhao YH, Srinivasan SG, Zhu YT, Valiev RZ, Gunderov DV (2004) Appl Phys Lett 84:592

64. Rösner H, Markmann J, Weissmüller J (2004) Phil Mag Lett $84: 321$

65. Meyers MA, Murr LE (1978) Acta Metall 26:951

66. Mahajan S, Pande CS, Imam MA, Rath BB (1997) Acta Mater 45:2633

67. Li S, Beyerlein IJ, Alexander DJ, Vogel SC (2005) Scripta Mater 52:1099
68. Li S, Beyerlein IJ, Bourke MAM (2005) Mater Sci Eng A 394:66

69. Li S, Beyerlein IJ, Necker CT, Alexander DJ, Bourke MA (2004) Acta Mater 52:4859

70. Agnew SR, Weertman JR (1998) Mater Sci Eng A 242:174

71. Huang WH, Chang L, Kao PW, Chang CP (2001) Mater Sci Eng A 307:113

72. Gholinia A, Bate P, Prangnell PB (2002) Acta Mater 50:2121

73. Gazder AA, Dalla Torre FH, Gu CF, Davies CHJ, Pereloma EV (2006) Mater Sci Eng A 415:126

74. Ferrasse S, Segal VM, Kalidindi SR, Alford F (2004) Mater Sci and Eng A 368:28

75. Gubicza J, Balogh L, Hellmig RJ, Estrin Y, Ungár T (2005) Mater Sci Eng A 334: 400-401

76. Cao WQ, Godfrey A, Liu W, Liu Q (2003) Mater Sci Eng A 360:420

77. Li S, Bourke MAM, Beyerlein IJ, Alexander DJ, Clausen B (2004) Mater Sci Eng A 382:217

78. Shih MH, Yu CY, Kao PW, Chang CP (2001) Scripta Mater 45:793

79. Wang YM, Ma E (2003) Appl Phys Lett 83:3165

80. Haouaoui M, Karaman I, Maier HJ, Hartwig KT (2004) Metall Mater Trans A 35:2935

81. Wang JT, Du ZZ, Kang F, Chen G (2006) Mater Sci For 663:503-504

82. Krishanaiah A, Chakkingal U, Venugopal P (2006) Mater Sci For 733:503-504

83. Valiev RZ, Alexandrov IV, Zhu YT, Lowe TC (2002) J Mater Res 17:5

84. Maier HJ, Gabor P, Gupta N, Karaman I, Haouaoui M (2006) Internat J.Fatigue 28:243

85. Dalla Torre FH, Pereloma EV, Davies CHJ (2006) Acta Mater 54:1135

86. Hart EW (1967) Acta Metall 15:351

87. Valiev RZ (2003) Adv Eng Mater 5:296

88. Vinogradov A, Ishida T, Kitagawa K, Kopylov VI (2005) Acta Mater 53:2181

89. Dalla Torre FH, Van Swygenhoven H, Victoria M (2002) Acta Mater 50:3957

90. Hollang L, Thiele E, Holste C, Brunner D (2006) Mater Sci Eng A 424:138

91. Zehetbauer M, Seumer V (1993) Acta Metall Mater 41:577

92. Wei Q, Cheng S, Ramesh KT, Ma E (2004) Mater Sci Eng 381:71

93. Wang YM, Ma E (2004) Appl Phys Lett 85:2750 